\title{
Distribution and role of calmodulin in tip growing hy- phae of Saprolegnia ferax ${ }^{1}$
}

\author{
YUAN Shen g, Ling LU, Sh а о в д XUE* \\ Department of Biology, Nanjing Normal University, Nan- \\ jing 210097, China \\ *Department of Biology, Beijing Normal University, Bei- \\ ring 100875, China
}

\begin{abstract}
Since direct staining of growing hyphae with trifluoperazine (TFP) could result in the migration of protoplasm in hyphae of water mold Saprolegnia ferax, an improved staining method for fixation of growing hyphae was developed. When hyphae of Saprolegnia ferax were pre-fixed with paraformaldehyde, the TFP fluorescence showed a clear tip-high $\mathrm{Ca}^{2+}$-activated calmodulin $(\mathrm{CaM})$ gradient. By indirect immunohistochemical staining, we proved that total CaM also mainly concentrated in the apex of hyphae. It is noticeble that when the hyphal tip growth ceased, the high intensity of TFP fluorescence usually disappeared in non-growing tips and became evident in the newly emerged growing tips, which implied that the concentration of $\mathrm{CaM}$ shifted in concord with the transfer of growing point in hyphae. $2 \times 10^{-5} \mathrm{~mol} / \mathrm{L} \mathrm{CaM}$ inhibitor TFP could reduce the tip growth rate and the percentage of growing hyphal tips to about $50 \%$, and induce multibranching of hyphal tips. These findings strongly suggest that the high concentration of calmodulin in the hyphal tip may be involved in regulation of hyphal tip growth.
\end{abstract}

Key words: Calmodulin, calcium, tip growth, trifluoperazine, Saprolegnia ferax.

1. The Project was supported by National Natural Science Foundation of China. We thank Dr. IB Heath of Department of Biology of York University, Canada, for providing the Saprolegnia ferax culture, valuable discussion of the manuscript and giving us some good suggestions and favors. 


\section{INTRODUCTION}

Fungal hyphae extend by tip growth and have a higher concentration of $\mathrm{Ca}^{2+}$ in their apices than their bases, a fact which is probably related to the importent role played by calcium in establishing and maintaining apical organization, morphogenesis, and growth[1-6]. To understand the the function of $\mathrm{Ca}^{2+}$ in hyphal tip growth, $\mathrm{Ca}^{2+}$-binding proteins must be identified and their functions determined. $\mathrm{CaM}$, a ubiquitous intracellular $\mathrm{Ca}^{2+}$-binding protein which functions to mediate many $\mathrm{Ca}^{2+}$-regulated processes in cells, naturally has been received a lot of attention. Some mycologists suggest that CaM may be involved in hyphal tip growth as shown by the effects of the CaM inhibitors, the phenothiazines[7-9]. In the plant kingdom, tip-growing cells, such as pollen tubes and root hairs, have been proved to have high concentration of $\mathrm{CaM}$ in their apices, which was considered to be linked to the modulation of tip growth[10,11]. However, in the myceteae kingdom, so far almost no one reported the distribution of CaM in the hyphal tips, excepted that of HauBer et al., who observed a non-polar distribution of CaM in hyphae stained directly with phenothianzine drugs[10]. So more data are needed to confirm and clarify the distribution and role of CaM in tip of growing hyphae.

\section{MATERIALS AND METHODS}

\section{Culture}

Saprolegnia ferax (Gruith) Thuret (ATCC No. 36051) was grown on dialysis membrane overlying an agar medium designated as $\mathrm{OM}$ (adjusted to $\mathrm{pH} 6.8$ with $\mathrm{KOH}$ ) by Heath and Greenwood[12]. Squares of membrane bearing hyphal tips were cut from the growing edge of the colony and allowed to recover for $30 \mathrm{~min}$ for further experiments[13].

\section{Localization of CaM}

(1) Immunohistochemical localization was done by the modified methods of Lin et al[11] and Suryanarayana and Thomas[14] and briefly was as follows: the growing hyphae were fixed immediately with $3 \%$ paraformaldehyde in $0.1 \mathrm{~mol} / \mathrm{L}$ phosphate buffer $(\mathrm{PB}, \mathrm{pH}$ 7.4) containing $0.002 \%$ $\mathrm{CaCl}_{2}$ for 6-7 h, washed in $\mathrm{PB}$ three times (10 min each); rinsed with $0.025 \mathrm{~mol} / \mathrm{L}$ hydroxylamine for $30 \mathrm{~min}$, washed; fixed onto $1 \%$ gelatin-coated slides, air-dried overnight, rinsed with lysis medium $\left(0.59 \mathrm{~mol} / \mathrm{L}\right.$ sorbitol, $0.05 \mathrm{~mol} / \mathrm{L} \mathrm{Na} \mathrm{EDTA}_{2} 0.05 \mathrm{~mol} / \mathrm{L} \mathrm{NaH} \mathrm{PO}_{4}, 0.00014 \mathrm{~mol} / \mathrm{L}$ $\beta$-mercaptoethanol, $0.001 \mathrm{~mol} / \mathrm{L} \mathrm{PMSF}, \mathrm{pH} 6.5$ ); treated for $30 \mathrm{~min}$ with $2 \mathrm{mg} / \mathrm{ml}$ driselase in lysis medium, washed; permeabilized for 30 min with cold methanol $\left(-20{ }^{\circ} \mathrm{C}\right)$, washed; rinsed with $4 \%$ $\mathrm{H}_{2} \mathrm{O}_{2}$ in $\mathrm{PB}$ for 10 min, washed; rinsed with normal chicken serum (at 1:100 dilution) for $10 \mathrm{~min}$, incubated with rabbit antiserum against pig brain calmodulin (1:50 dilution) for about $40 \mathrm{~h}$ at $4^{\circ} \mathrm{C}$, washed; incubated with peroxidase-conjugated protein A (Staphylococcus aureus, 1:40 dilution) for $1 \mathrm{~h}$, washed; refixed with 2.5\% glutaraldehyde in PB for 10 min,washed; incubated with $0.05 \%$ 3, 3-diaminobenzidine- $4 \mathrm{HCl}$ in $\mathrm{PB}(\mathrm{pH} 7.2)$ plus $0.01 \% \mathrm{H}_{2} \mathrm{O}_{2}$ for $2 \mathrm{~min}$, washed; mounted with $50 \%$ glycerine in $\mathrm{PB}$, sealed by fingernail polish and examined with a Olympus BH-2 light microscope. For control experiments, the hyphae were incubated with pre-immune serum or with antiserum against pig brain CaM which had been previously absorbed with excess antigen $(100 \mu \mathrm{g} / \mathrm{ml}$ pig brain $\mathrm{CaM}$ ).

(2) TFP fluorescent localization was done by a modified HauBer's method[10]: the hyphae on the membrane were mounted in liquid $\mathrm{OM}$ in a slide chamber and fresh $\mathrm{OM}$ was drawn through it 
for $30 \mathrm{~min}$ to allow the cells to resume growth[13] unless elsewhere indicated. The growing hyphae were fixed by flowing approximately $0.3 \mathrm{ml} 5 \%$ glutaraldehyde in $1 / 15 \mathrm{~mol} / \mathrm{L}$ phosphate buffer $(\mathrm{pH}$ 7.0) through the chamber for $10 \mathrm{~min}$, followed by drawing the same volume of $10^{-4} \mathrm{~mol} / \mathrm{L}$ TFP in OM through it for a further $10 \mathrm{~min}$, and then examined with a Nikon Labophot microscope using CF fluor objectives with phase-contrast and epi-fluorescence optics with a UV filter block (EX330-380, DM400, A420). As a control, hyphae fixed with glutaraldehyde were treated with OM instead of TFP for 10 min. All micrographs were recorded with Ilford HP5 plus (ASA 400) black and white films processed with D-76 Developer.

\section{Effects of TFP on hyphal tip growth}

Growing hyphae were flowed with TFP in OM at $0,10^{-6}, 10^{-5}, 2 \times 10^{-5}, 5 \times 10^{-5} \mathrm{~mol} / \mathrm{L}$ through the chamber for $30 \mathrm{~min}$ and then the growth rate was measured by the examination of the changes of the length of individual hyphal tips, selected randomly, 2 min apart with an ocular micrometer. The percentage of growing hyphal tips in total examined hyphal tips at various concentrations of TFP in OM was monitored by counting the numbers of growing and non-growing hyphal tips under the microscope. Morphological changes of hyphal tips were photographed with the Nikon Labophot microscope as described.

\section{Chemicals}

Rabbit antiserum against pig brain $\mathrm{CaM}$ and peroxidase-conjugated protein A (Staphylococcus aureus) were gifts from Professor Zhou Xi of the Department of Agronomy of Nanjing Agricultural University. Some supplies were obtained as follows: TFP (sigma), glutaraldehyde (E. Merck), driselase (Kyowa Hakko Kogyo Co., Ltd, Tokyo ).

\section{RESULTS}

When growing hyphae were fixed with glutaraldehyde and then stained with $10^{-4}$ mol /L TFP, they showed a clear TFP fluorescence gradient from tip to base (Fig 1). The most intense fluorescence of TFP mainly existed in the hyphal tip. Beyond $30 \mu \mathrm{m}$ of the hyphal tip the fluorscence became very weak and uniform. It was very interesting to note that if hyphae were only allowed to recover for $10 \mathrm{~min}$, but not $30 \mathrm{~min}$, prior to fixation and staining (see materials and methods) in order to show the very short emerging growing tip, TFP fluorescence was mainly concentrated in newly emerged growing tips, but not in non-growing tips resulted from the transfer of the hyphae to the slide (Fig 2). If hyphae were stained directly with $10^{-4} \mathrm{~mol} / \mathrm{L}$ TFP without fixation, TFP immediately stopped the tip growth, and caused the redistribution, backward contraction or vacuolization of cytoplasm so that the TFP fluorescence gradient became disturbed and the apical concentration of fluorescence in hyphal tips was no longer evident (data not shown). In the control experiment, glutaraldehyde-fixed hyphae treated with OM, instead of TFP in OM, did not give any detectable autofluorescence (Fig 3).

By Immunohistochemical locolization, we confirmed that the above TFP fluorescence patterns did really reflect the distribution of $\mathrm{CaM}$ in hyphae. When the hyphae were stained with antiserum against pig brain CaM, reaction product was found mainly in the hyphal tip, and appeared as a gradient of brownish product from tip to base (Fig 4). A similar result was also observed in the branching hyphal 
CaM in tip growing hyphae
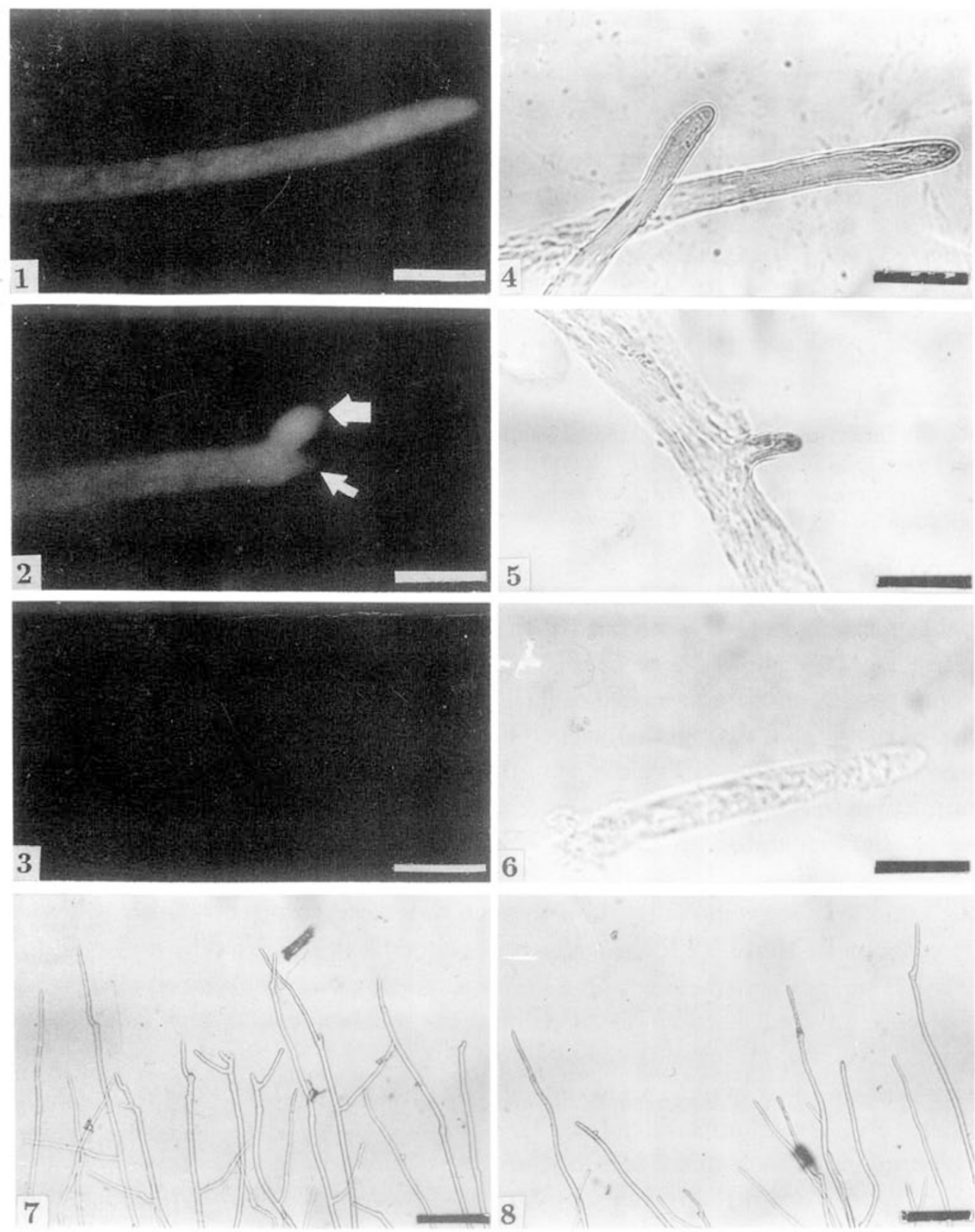
tip (Fig 5). In the control experiment, when hyphae were incubated with preimmune serum (or with antiserum against CaM which had been pre-absorbed with $100 \mu \mathrm{g} / \mathrm{ml}$ pig brain CaM), no reaction product was found (Fig 6).

The tip growth of hyphae of Saprolegnia ferax was found to be affected by TFP. The tip growth rate of individual hyphae and the percentage of growing hyphal tips were inhibited by the concentration of TFP above $10^{-6} \mathrm{~mol} / \mathrm{L}$ (Tab 1 ). At $2 \times 10^{-5}$ $\mathrm{mol} / \mathrm{L}$ TFP, the growth rate of hyphae slowed down to about $50 \% .5 \times 10^{-5} \mathrm{~mol} / \mathrm{L}$ TFP could immediately terminate the tip growth of hyphae. TFP also affected the morphology of hyphae and induced multibranching of hyphae. The numbers of branching tips under $2 \times 10^{-5} \mathrm{~mol} / \mathrm{L}$ TFP were greatly increased than that of the control (compare Fig 7, 8).

\section{DISCUSSION}

CaM inhibitor phenothiazines drugs such as TFP could be used as fluorescent probes for calmodulin to determine $\mathrm{Ca}^{2+}-\mathrm{CaM}$ site in cells[15]. HauBer et al. (1984)[10] even reported that CaM shown by phenothiazine fluorescence did not appear as a gradient from tip to base in growing hyphae of water mold Achyla sp., quite different from tip growing cells of plant such as pollen tubes and roots hairs. However, we noticed that the materials used for the experiments made by HauBer et al were growing hyphae without pre-fixation, a condition which might lead to the possibility that the fluorescence pattern of phenothiazines reported by them did not represent the normal distribution of CaM in growing hyphal tips. Actually, as we have mentioned in the section on Results, the direct staining of hyphae with TFP could cause the redistribution and backward contraction or vacuolization of cytoplasm, leading to the disturbance of the true TFP fluorescent pattern of hyphae. An improved staining method for fixation of growing hyphae was, therefore, developed. When hyphae were pre-fixed with glutaraldehyde, migration of protoplasm did not

$\triangleleft$ Fig 1 . TFP staining pattern of growing tip of hyphae pre-fixed with glutaraldehyde, $\times 630$. bar $=20 \mu \mathrm{m}$.

Fig 2. TFP staining pattern of hyphae pre-fixed with glutaraldehyde but only recovered for $10 \mathrm{~min}$ before fixation and staining which showed that the fluorescence disappeared in the non-growing tip (small arrow) and appeared in the emerging growing tip (thick arrow) of hyphae, $\times 630$. bar $=20 \mu \mathrm{m}$.

Fig 3. Autofluorescence patterns of hyphae pre-fixed with glutaraldehyde, $\times 630$. bar $=20$ $\mu \mathrm{m}$.

Fig 4. Hyphal tip stained with antiserum against CaM. $\times 630$. bar $=20 \mu \mathrm{m}$

Fig 5. Branching hyphal tip stained with antiserum against CaM. $\times 630$. bar $=20 \mu \mathrm{m}$.

Fig 6. Hyphal tip stained with pre-immune serum, $\times 630$. bar $=20 \mu \mathrm{m}$.

Fig 7 Multibranching hyphae caused by incubating with $2 \times 10^{-5} \mathrm{~mol} / \mathrm{L}$ TFP for $30 \mathrm{~min}$. $\times 50$. bar $=200 \mu \mathrm{m}$.

Fig 8. Normal growing hyphae without treatment of TFP. $\times 50$. bar $=200 \mu \mathrm{m}$ 
$\mathrm{CaM}$ in tip growing hyphae

occur and TFP fluorescence appeared in a gradient pattern from tip to base in growing hyphae of water mold Saprolegnia ferax (Fig 1,2). Heath[16] recently pointed out that growing hyphae are extremely labile and processes of staining and observation could easily and rapidly halt growth and thus reveal patterns which are not necessarily characteristic to normal tip growth. Therefore, it seems necessary to pre-fix growing hyphae with fixative to prevent protoplasm movement when the fluorescent probes used for cytochemical localization are toxic to hyphae.

Considering phenothiazine drugs could only give the information of $\mathrm{Ca}^{2+}$-activated $\mathrm{CaM}$ site and may be not completely specific to CaM[17], we further determined the distribution of total CaM in tip growing hyphae by immunohistochemical method, which could be used for the localization of both inactivated and $\mathrm{Ca}^{2+}$-activated $\mathrm{CaM}$ sites[18]. Thus, a gradient of brownish reaction product from tip to base in hyphal tips was observed (Fig 4,5), revealing the concentration of total CaM mainly in the apex of hyphae. It is interesting to note that, for the first time, we found that the distribution of tip-high concentration of $\mathrm{CaM}$ was correlated with the transfer of growing point in hyphae. When the hyphal tip growth ceased, the high intensity of TFP fluorescence usually disappeared in non-growing tips and became evident in the newly emerged growing tips (Fig 2). Thus it is apparent that CaM is related to tip growth of hyphae. This conclusion is further supported by the inhibition of TFP to CaM-mediated activation through the $\mathrm{Ca}^{2+}$-dependent interaction of TFP with CaM. We have demonstrated that TFP could reduce the tip growth rate and the percentage of growing tips(Tab 1). Meanwhile, TFP also induced multibranching of hyphae (Fig 7) of the Oomycetes Saprolegnia ferax, which has not been a reported before.

Tab 1. Effects of TFP on hyphal tip growth of Saprolegnia ferax

\begin{tabular}{|c|c|c|c|c|c|c|}
\hline & \multicolumn{3}{|c|}{$\begin{array}{l}\text { Growth rates } \\
(\mu \mathrm{m} / \mathrm{min})\end{array}$} & \multicolumn{3}{|c|}{$\begin{array}{c}\text { Percentage of growing } \\
\text { hyphal tips }\end{array}$} \\
\hline Treatment & $\mathrm{n}^{*}$ & Mean \pm SD. & $\begin{array}{c}\text { Inhibition } \\
(\%)\end{array}$ & $\begin{array}{l}\text { No. of } \\
\text { total } \\
\text { tips }\end{array}$ & $\begin{array}{l}\text { No. of } \\
\text { growing } \\
\text { tips }\end{array}$ & $\begin{array}{c}\text { Percentage } \\
\text { of growing } \\
\text { tips }(\%)\end{array}$ \\
\hline control & 23 & $14.95 \pm 1.90$ & 0 & 45 & 39 & 86.7 \\
\hline $10^{-6} \mathrm{~mol} / \mathrm{L}$ TFP & 25 & $11.36 \pm 2.15$ & 24.0 & 30 & 15 & 50.0 \\
\hline $10^{-5} \mathrm{~mol} / \mathrm{L}$ TFP & 25 & $10.00 \pm 2.49$ & 33.1 & 30 & 12 & 40.0 \\
\hline $2 \times 10^{-5} \mathrm{~mol} / \mathrm{L} \mathrm{TFP}$ & 31 & $7.71 \pm 3.29$ & 48.4 & 45 & 18 & 40.0 \\
\hline $5 \times 10^{-5} \mathrm{~mol} / \mathrm{L} \mathrm{TFP}$ & 30 & 0 & 100.0 & 45 & 0 & 0 \\
\hline
\end{tabular}

* $\mathrm{n}$ : The number of examined growing hyphal tips selected randomly under the microscope.

If CaM plays an importent role in hyphal tip growth,the followings are possible mechanisms of action: (1). CaM may be involved in secretory system in the extreme apex of hyphae and regulates the formation of the new cell wall. It is known 
that the most apical 1-2 $\mu \mathrm{m}$ area of the tip is filled almost exclusively by a high density of Golgi body derived secretory vesicles known as wall vesicles, which bring to the cell surface raw materials (precusors, products, enzymes) needed to construct the cell wall for the maintenance of hyphal tip growth by exocytosis[19]. CaM has been implicated in numerous secretory systems[20], including cellulase secretion by Trichoderma reesii [21], and possibly in association with wall-hydrolysing enzymes of water mold Saprolegnia ceous[14]. (2) CaM may also control the extensibility of the actin cap in hyphal tips. It is clear that $\mathrm{F}$-actin is concentrated in growing hyphal tip and forms a cap-like structure to resist the turgor pressure for supporting of hyphal tip growth[16]. In turn, the function of actin is regulated by CAM[22].

\section{REFERENCES}

[1] Reissig JL, Kiney SG. Calcium as a branching signal in Neurospora crassa. J Bacteriol 1983; 154:1397-402.

[2] Schmid J, Harold FM. Dual roles for calcium ions in apical growth of Neurospora crassa. J Gen Microbiol 1988; 134:2623-31.

[3] Dicker JW, Turian G. Calcium deficiencies and apical hyperbranching in wild-type and "frost" and "spray" morphological mu-tants of Neurospora crassa. J Gen Microbiol 1990; 136:1413-20.

[4] Robson GD, Wiebe MG, Trinci APJ. Low calcium concentration induce increased branching in Fusarium graminearum. Mycol Res 1991; 95:561-5.

[5] Yuan S, Heath IB. Chlortetracycline staining patterns of growing hyphal tips of the Oomycetes Saprolegnia ferax. Exp Mycol 1991; 15:91-102.

[6] Jackson SL, Heath IB. Roles of calcium ions in hyphal tip growth. Microbiol Rev 1993; 57:36782.

[7] Turin G, Ortega Perez R. XIII International Congress of Microbiology. Boston Massachusetts USA Abstract 1982: p 75.

[8] Ortega Perez R, Turin G. Cytomorphological defects produced by anti-calmodulin agents in outgrowing germ tubes and elongation hyphae of Neurospora crassa. Cytobios 1987; 49:137-45.

[9] St. Leger RJ, Butt TM, Orlow SJ et al. Second messenger involvement in differeniation of the entomopathogenic fungus Metarhizium anisopliae. J Gen Microbiol 1990; 136:1779-89.

[10] HauBer I, Herth W, Reiss HD. Calmodulin in tip-growing plant cells, visualized by fluorescing calmodulin-binding phenothiazines. Planta 1984; 162:33-9.

[11] Lin CT, Sun DY, Song GX et al. Calmodulin: localization in plant tissues. J Histochem Cytochem 1986; 34:561-7.

[12] Heath IB, Greenwood AB. Electron microscopic observation of dividing somatic nucler in Saprolegnia. J Gen Microbiol 1968; 53:287-9.

[13] Yuan S, Heath IB. A comparison of fluorescent membrane probes in hyphal tips of Saprolegnia ferax. Exp Mycol 1991; 15:103-15.

[14] Suryanarayana K, Thomas DDD. Asexual spore release from Saprolegnia ceous water moulds: involvement of calmodulin. J Gen Microbiol 1986; 132:593-8.

[15] Nelson GA, Andrews ML, Karnovsky MJ. Participation of calmodulin in immunoglobulin capping. J Cell Biol 1982; 95:771-80.

[16] Heath IB. The roles of actin in tip growth of fungi. Int Rev Cytol 1990; 123:95-127.

[17] Klee CB. Interaction of calmodulin with $\mathrm{Ca}^{2+}$ and target proteins. In: Cohen P, Klee CB eds. "Calmodulin'. The Netherlands: Elsevier Sci Publishers BV 1988; 35-56.

[18] You JS, Li SW, Wang DS et al. The distribution of calmodulin and $\mathrm{Ca}^{2+}$-activated calmodulin in cell cycle of mouse erythroleukemia cells. Cell research 1990; 1:89-94. 
$\mathrm{CaM}$ in tip growing hyphae

[19] Bartnicki-Garcia S. Role of vesicles in apical growth and a new mathematical model of hyphal morphogenesis. In: Heath IB ed. "Tip growth of plant and hyphal cells" . San Diego: Academic Press, 1990: 211-32.

[20] Steinhardt RA, Alderton JM. Calmodulin comfers calcium sensitivity on secretory exocytosis. Nature London 1982; 295:154-5.

[21] Hill TW, Waggener RG. Cellulase secretion by Trichoderma reesii is inhibited by anti-calmodulin drugs. Mycological Society of America Newsletter 1984; 35(1):28.

[22] Gratzer WB, Bain AJ. Calmodulin and cytoskeletal function. In: Cohen P, Klee CB eds "calmodulin". the Netherlands: Elsevier Sci Publishers BV 1988: 329-40.

Received 21-3-1995. Revised 21-11-1995. Accepted 7-12-1995. 